real patients, competing agendas, and paucity of evidence, one might easily get despondent despite a strong desire to achieve the best for one's patients.

McLandburgh Wilson said 'Twixt the optimist and pessimist the difference is droll: the optimist sees the doughnut, but the pessimist sees the hole'. ${ }^{8}$ We have a professional responsibility to remain optimistic, while seeking robust evidence to inform our primary healthcare practice and our commissioning of interventions to modify patients' lifestyles.

\section{Helen Smith,}

Chair of Primary Care, Brighton \& Sussex

Medical School.

\section{Provenance}

Commissioned; not peer reviewed.

\section{REFERENCES}

1. Royal College of General Practitioners. Oral contraceptives and health. London: Pitman Medical, 1974.

2. Iversen L, Hannaford PC, Lee AJ, et al. Impact of lifestyle in middle-aged women on mortality: evidence from the Royal College of General Practitioners' Oral Contraception Study. Br J Gen Pract 2010; 60: $563-569$.

3. National Institute for Health and Clinical Excellence. Brief interventions and referral for smoking cessation in primary care and other settings. London: NICE, 2006.

4. National Institute for Health and Clinical Excellence. Four commonly used methods to increase physical activity: brief interventions in primary care, exercise referral schemes, pedometers and community-based exercise programmes for walking and cycling. London: NICE, 2006.

5. National Institute for Health and Clinical Excellence. Alcohol-use disorders - preventing the development of hazardous and harmful drinking. London: NICE, 2010.

6. National Institute for Health and Clinical Excellence. Obesity: guidance on the prevention, identification, assessment and management of overweight and obesity in adults and children. London: NICE, 2006.

7. Mercer S. How useful are clinical guidelines for the management of obesity in general practice? $\mathrm{Br} \mathrm{J} \mathrm{Gen}$
Pract 2009; 59(568): 863-868.

8. Wilson M. Optimist and Pessimist. http://www.anvari.org/fortune/Sarcasm/719_twixt-theoptimist-and-pessimist-the-difference-is-droll.html (accessed 12 Jul 2010).

DOI: 10.3399/bjgp10X515034

\section{ADDRESS FOR CORRESPONDENCE}

\section{Helen Smith}

Chair of Primary Care, Room 319,

Mayfield House, University of Brighton,

Falmer, BN1 9PH

E-mail: h.e.smith@bsms.ac.uk

\title{
Cardiovascular disease beyond the QOF
}

\section{NATIONAL POLICY}

The aim of current Department of Health (DH) policy on cardiovascular disease in England is to improve prevention and treatment in parallel. ${ }^{1}$ The vascular programme within the $\mathrm{DH}$ has made major efforts in recent years to bring prevention efforts together across the whole spectrum of cardiovascular disease, including heart disease, stroke, diabetes, and chronic kidney disease, to combine these with the national clinical directors' work on this programme. In the past, the individual National Service Frameworks ${ }^{1-3}$ have all emphasised the need for prevention, but with slight differences in detail. The current NHS Health Check $^{4}$ programme is evidence of this joined-up approach.

\section{HEALTH AND SOCIAL IMPACT OF CARDIOVASCULAR DISEASE}

Comparing 2005-2007 with 1995-1997, there were, on average, 31000 fewer cardiovascular deaths each year. But there is no room for complacency. Despite the almost $50 \%$ reduction in cardiovascular mortality over the last decade, the reductions have not been equally distributed. There has been a narrowing of the absolute gap in death rates between the spearhead primary care trusts and the English average, and we are on target to reduce the gap by $40 \%$ by 2010, but there remains a major differential between the 1st and 5th quintile of deprivation (Department of Health, unpublished data, 2008). Further improvement will require crossgovernment activity and clinicians need to continue to take into account issues such as deprivation, ethnicity, sex, and age when making clinical decisions with patients and working with them regarding lifestyle and interventions that reduce risk.

\section{IMPACT OF PRIMARY CARE ACTIVITY}

We know from a range of data that primary care has had a substantial impact on cardiovascular burden across the nation where clinical enthusiasm, incentive schemes, and national policies have all played their part. One example is in the prescription of statins where we have seen over a sixfold increase in prescribing, ${ }^{5}$ and a recent comparison of data from 14 developed nations showed that the UK ranks second in terms of utilisation.

The improvement in cholesterol and blood pressure management seen in primary care has been substantial; however, we also know from the Health Survey for England ${ }^{7}$ and cohort studies $^{8}$ that there has been little improvement in the nation's blood pressure, although the percentage of men on treatment has 
increased. We also know that the prevalence of cardiovascular disease reported in Quality and Outcomes Framework (QOF) registers falls well short of the predicted prevalence in many areas of the country where we need to draw the conclusion that case ascertainment remains less than ideal.

\section{FOCUS GOING FORWARD}

So where should we be concentrating our efforts for the future? Clearly some of the agenda involves doing more of the same while raising the bar for ourselves at both national and local levels.

GPs, primary care cardiovascular leads, and practice teams already do a tremendous amount of work to help implement all the $\mathrm{DH}$ initiatives, but clearly more is needed. There needs to be a grassroots approach. The Royal College of General Practitioners (RCGP) Curriculum is the first rung in the ladder in terms of addressing the UK-wide quality agenda (www.rcgp-curriculum.org.uk), and support for associates in training and newly qualified GPs in the 'first 5 years' recognises the continuing professional development (CPD) needs of trainees and newly qualified GPs (http://www.rcgp.org.uk/ait).

Primary Medical Care Provider Accreditation (PMCPA) has been developed by the RCGP and has the aim of providing a system which will help to improve the quality and reduce the variability of care across the 8300 GP practices in England (http://www.rcgp.org.uk/pmcpa). PMCPA is an opportunity for practices to gain recognition for good organisation and practice governance though a quality practice framework that addresses domains such as health inequalities and the practice as a learning organisation.

The Quality Practice Award (http://www.rcgp.org.uk/qpa) is a criterionbased quality accreditation process which recognises excellence. The CPD needs of GPs are being addressed by the RCGP elearning programmes and are supported by the credit-based system of learning which recognises the implementation of learning in practice (http://www.eIfh.org.uk/projects/egp/). Basically, 1 hour of learning is 1 credit, but if the GP demonstrates that the learning has been used in practice, then the GP can claim 2 credits. Solid links with the RCGP's Patient Partnership Group and the setting up of the GP Foundation which supports practice nurses, physician assistants, and practice managers illustrates the importance of a multidisciplinary approach.

The RCGP recognises both the importance of clinical audit and research, particularly through its Clinical Innovation and Research Centre, and the need to influence practice-based commissioning. This is especially relevant at the level of the federated practices, with excellent examples of producing high-quality output from such units of general practices where additional diagnostics and population level inputs, such as cardiac rehabilitation and preventive exercise programmes, may be developed.

Beyond that, the impending financial climate will require a focus on other imperatives that have the potential to drive up quality and at the same time drive down longer-term spending in the NHS. ${ }^{9}$ Four clinical areas deserve consideration. The first is to ask whether we can improve the detection and management of people with atrial fibrillation. The most recent data from the BAFTA trial ${ }^{10}$ demonstrates that warfarin is far superior to aspirin in the prevention of strokes and that there is consistent benefit even in older people. The National Institute for Health and Clinical Excellence (NICE) estimates that approximately $40 \%$ of patients in whom warfarin is indicated are not receiving it, amounting to some 166000 patients nationally.

NHS Improvement has projects which use the Guidance on Risk Assessment and Stroke Prevention for Atrial Fibrillation (GRASP-AF) tool, which is a MIQUEST query that interrogates practice systems to find patients with atrial fibrillation that have a $\mathrm{CHADS}_{2}$ score of 2 or more, indicating high stroke risk. This provides a prediction score that estimates the risk of stroke in patients with non-rheumatic atrial fibrillation who would be suitable for anticoagulation. This tool is available free from NHS Improvement. ${ }^{11}$
In the management of heart failure, patients on GP heart failure registers, representing prevalent cases of heart failure, have a 5 -year survival rate of $58 \%$ compared with $93 \%$ in the age and sexmatched general population. ${ }^{12}$ Only a minority of patients have access to cardiac rehabilitation and there is poor adherence to medication in patients with heart failure. Locally-defined initiatives that include joint working across primary and secondary care, the development of care plans, and improved selfmanagement should be encouraged.

In patients with hypertension, information from two major British cohort studies show that half the British population were found to be hypertensive and only half of these were on treatment. Only small proportions were adequately controlled. ${ }^{8}$ It is anticipated that the NHS Health Check programme will be a major lever, but there needs to be stricter adherence to the clinical guidelines in achieving adequate control. Improvements measured under QOF have reached a plateau over recent years and there remains a lot to be done.

A key area is the prescribing of statins where there remains unacceptable variation in the use of the more costly statins. The NHS Institute, in 2007 , calculated that we could save at least $£ 85$ million across England by switching to generic statins alone, and many regarded these as conservative estimates. ${ }^{13}$

Progress has been made but it varies considerably by region in England. A clinical area where statin prescribing is particularly important is in familial hypercholesterolaemia which is hugely under diagnosed. In familial hypercholesterolaemia, it may well be legitimate to use non-generic statins, but equally important is improved identification of affected families. Although more than 120000 people in the UK have the disease, a 2008 survey of lipid clinics indicated that 15000 cases are known at most. Thus, around $90 \%$ of people with familial hypercholesterolaemia go undetected, and many may be disabled or die from chronic heart disease early in life, often in their 40 s or 50 s, sometimes earlier. ${ }^{14}$ 
A recently published Primary Care Service Framework ${ }^{15}$ outlines how primary care might contribute to this work programme. Heart UK, the cholesterol charity, have recently published a guideline implementation toolkit ${ }^{16}$ that corresponds to the NICE guideline for familial hypercholesterolaemia. ${ }^{14}$

We know that the common aims of improving diet, exercise, and smoking are paramount and, as always, the challenge is to engage better with people so that they take responsibility for their own health in order to improve their physical and psychological well-being. Cardiac rehabilitation programmes provide for much of this, but it is also clear that many patients prefer to undertake these programmes in their own homes or, at least, near to where they live. A recent Cochrane Review demonstrated that home-based programmes can be just as effective has hospital-based programmes and might well improve access issues. ${ }^{17}$

The Department of Health is currently developing a Commissioning Pack for Cardiac Rehabilitation that addresses these issues as well as the cost-efficacy of new models of provision.

\section{Roger Boyle,}

National Director for Heart Disease and Stroke.

\section{Steve Field,}

Chairman of the Royal College of General

Practitioners (RCGP).

\section{Nigel Sparrow,}

Chair of the RCGP Professional Development Standards Board.

\section{Amanda Howe,}

Honorary Secretary of the RCGP.

\section{Imran Rafi,}

Medical Director RCGP Clinical innovation and Research.

\section{Provenance}

Commissioned; not peer reviewed.

\section{REFERENCES}

1. Department of Health. Coronary heart disease: national service framework for coronary heart disease - modern standards and service models. London: Department of Health, 2000.

http://www.dh.gov.uk/en/Publicationsandstatistics/Publ ications/PublicationsPolicyAndGuidance/DH_4094275 (accessed 30 Jun 2010).

2. Department of Health. The National Service Framework for diabetes. London: Department of Health, 2007. http://www.dh.gov.uk/en/Publicationsandstatistics/Publ ications/PublicationsPolicyAndGuidance/Browsable/D H_ 4096591 (accessed 30 Jun 2010).

3. Department of Health. National Service Framework for renal services - part two: chronic kidney disease, acute renal failure and end of life care. London: Department of Health, 2005.

http://www.dh.gov.uk/en/Publicationsandstatistics/Publ ications/PublicationsPolicyAndGuidance/DH_4101902 (accessed 30 Jun 2010)

4. NHS Health Check.

http://www.improvement.nhs.uk/nhshealthcheck/ (accessed 12 Jul 2010).

5. Care Quality Commission. Closing the gap. Tackling cardiovascular disease and health inequalities by prescribing statins and stop smoking services. http://www.cqc.org.uk/_db/_documents/Closing_the_g ap.pdf (accessed 12 Jul 2010).

6. Walley T, Folino-Gallo P, Schwabe U, van Ganse E on behalf of the EuroMedStat group. Variations and increase in use of statins across Europe: data from administrative databases. BMJ 2004; 328: 385-386.

7. The NHS Information Centre for Health and Social Care. Health Survey for England - 2008 trend tables. http://www.ic.nhs.uk/statistics-and-datacollections/health-and-lifestyles-related-surveys/healthsurvey-for-england/health-survey-for-england--2008trend-tables (accessed 30 Jun 2010).

8. Patel R, Lawlor DA, Whincup P, et al. The detection, treatment and control of high blood pressure in older British adults: cross-sectional findings from the British Women's Heart and Health Study and the British Regional Heart Study. J Hum Hypertens 2006; 20(10): 733-741.

9. DH/NHS Finance, Performance \& Operations. Revision to the Operating Framework for the NHS in England 2010/11. London: Department of Health, 2010. http://www.dh.gov.uk/en/Publicationsandstatistics/Publi cations/PublicationsPolicyAndGuidance/DH_110107 (accessed 30 Jun 2010).

10. Mant J, Hobbs FD, Fletcher K, et al. Warfarin versus aspirin for stroke prevention in an elderly community population with atrial fibrillation (the Birmingham Atrial Fibrillation Treatment of the Aged Study, BAFTA): a randomised controlled trial. Lancet 2007; 370(9586): 493-503.

11. NHS Improvement. Guidance on Risk Assessment and Stroke Prevention for Atrial Fibrillation (GRASP-AF). Leicester: NHS Improvement. http://www.improvement.nhs.uk/graspaf/ (accessed 30 Jun 2010).

12. Hobbs FD, Roalfe AK, Davis RC, et al. Prognosis of allcause heart failure and borderline left ventricular systolic dysfunction: 5 year mortality follow-up of the Echocardiographic Heart of England Screening Study (ECHOES). Eur Heart J 2007; 28(9): 1128-1134.

13. NHS Institute for Innovation and Improvement. NHS better care, better value indicators. Coventry: NHS Institute for Innovation and Improvement, 2007. http://www.productivity.nhs.uk/ (accessed 30 Jun 2010).

14. National Institute for Health and Clinical Excellence. Identification and management of familial hypercholesterolaemia: NICE clinical guideline 71 London: NICE, 2008. http://guidance.nice.org.uk/CG7 (accessed 30 Jun 2010).

15. NHS Primary Care Commissioning. Primary Care Service Framework: familial hypercholesterolaemia. http://www.pcc.nhs.uk/uploads/commissioning/2010/0 2/primary_care service framework familial_hypercho lesterolaemia.pdf (accessed 12 Jul 2010).

16. Heart UK. Heart UK FH GT toolkit. Maidenhead: Heart UK. http://www.heartuk.org.uk/FHToolkit/ (accessed 30 Jun 2010).

17. Dalal HM, Zawada A, Jolly K, et al. Home based versus centre based cardiac rehabilitation: Cochrane systematic review and meta-analysis. BMJ 2010; 340:b5631. DOI: 10.1136/bmj.b5631.

DOI: 10.3399/bjgp10X515043

\section{ADDRESS FOR CORRESPONDENCE}

\section{Imran Rafi}

Medical Director RCGP Clinical innovation and Research, 31 Southampton Row, Holborn, London WC1B 5JH.

E-mail: irafi@sgul.ac.uk 